\title{
Construindo o futuro, significado dos 40 anos da Pós-graduação da EEFE-USP e contextualização histórica: Universidade e ciência
}

\section{Contextualização histórica, importância da Universidade e papel da Pós-graduação na formatação da ciência}

A Universidade tem por meta o desenvolvimento do "novo", da descoberta de rumos e busca de procedimentos, interagindo desta maneira no sistema de Ciência e Tecnologia (C\&T), numa sociedade em permanente transformação, em acordo com SCHENBERG ${ }^{1}$. Ensino, pesquisa e prestação de serviços à comunidade nas áreas associadas correspondem bem ao espírito das concepçóes de Humbolt (1767 -1835), fundador da Universidade de Berlim, claramente aplicadas já no inicio século XIX, e que se espalhou pelo mundo acadêmico contemporâneo. A Humboldt devemos a fundamentação do conceito de formação, ("Bildung") referência a um dos alicerces estruturantes da Universidade. Naturalmente, essas ideias já foram incorporadas e refletem os atuais objetivos da Universidade da Era Moderna, constando de maneira clara nas normas e ideários destas instituiçôes.

Marques et al. $^{2}$ descrevem que a história da Universidade é também a história da Ciência, que por sua vez corresponde à trajetória dos progressos da humanidade. Começou a ser escrita lá atrás não como ciência, mas como consequência da aprendizagem prática do Homem e da transmissão dos seus conhecimentos e práticas. Desde esses tempos, técnicas, habilidades e instrumentos permitiram que o ser humano evoluísse, civilizaçóes surgissem e o legado foi-se acumulando de maneira dispersa, pulverizado, mas, aos poucos, foi sendo recolhido, catalogado, sistematizado e compendiado por escribas, muçulmanos e monges copistas. A academia e o liceu tornaram-se, por conseguinte, fóruns naturais e espaços adequados, abertos e frutíferos para o diálogo, a discussão e a produção de teses filosóficas, políticas, sociais ou científicas, em acordo com Chaparro ${ }^{3}$. Em todos os tempos sempre existiram escolas onde os mestres ensinavam seus discípulos. Na Idade Média a ciência não tinha tanta liberdade de ação, por causa da Igreja impor uma verdade muitas vezes não aceita e, assim, gerando o descaso com todo o conhecimento produzido. $\mathrm{O}$ conhecimento finalmente saiu dos mosteiros para as catedrais, atingindo novos ambientes sociais e foi entre o século XII e o século XV que a "Escola Capitular de Nôtre-Dame de Paris" se tornou uma das primeiras universidades, onde mestres e graduados ensinavam ainda no modelo papal, ligado à Igreja. Outro modelo, o imperial, surgiu em Bolonha, caracterizado pelos colégios universitários ligados às naçôes. Na Inglaterra ocorreu outra formação ainda mais independente, tendo Oxford nascido da reuniáo de estudantes que procuravam mestres nos colégios medievais e se hospedavam nos "halls" construídos ao seu redor, em acordo com PESET ${ }^{4}$. No final do século XIV o Santo Ofício já não conseguia segurar os avanços da produção de novos conhecimentos e com isso a universidade medieval entra em declínio, conforme Marques et al. ${ }^{2}$. No século XV há um notório progresso em todos os campos do conhecimento, caracterizando o Renascimento. O conhecimento volta com sua essência de descobrir e ousar com a pesquisa, e o mundo novamente volta a crescer fora do sistema dogmático que a Igreja constituía. A pesquisa fundamentada na transmissão do saber e a extensão cultural interagindo com a sociedade começam a estruturar-se. Assim surgiu a diferença para que a sociedade tivesse a chance de conhecer um mundo ainda tão novo. Nessa perspectiva, a oportunidade que hoje a Universidade no mundo contemporâneo nos oferece dá-se fundamentalmente por vivermos, neste século XXI, numa "Sociedade do Conhecimento".

Assim, entre as tarefas atuais da Universidade, considerando a realidade da globalizaçáo e dos valores da sabedoria, seria definir qual o verdadeiro papel dessa instituição. Da mesma forma que 
a humanidade já assistiu e conviveu com várias revoluçóes, entre elas a agrícola e a industrial, vive-se hoje a revolução do conhecimento, em acordo com Giorgetti De Brito5, fato este que coloca uma dimensão nova para o tema central de que se ocupa a Universidade. O conhecimento, ainda segundo o Autor, "é ao mesmo tempo crucial para a produção, geração de riqueza e o desenvolvimento, o que implica na necessidade de açôes rápidas e eficientes para que a Universidade possa continuar a desempenhar seu papel fundamental de formar profissionais com visäo critica em diversas áreas do conhecimento".

Discutem ainda Marques et al. ${ }^{2}$, que a Universidade, diante do desafio central para os propósitos da formação, preparação e treino de jovens, procura estrategicamente definir os seus ideais de pesquisar, ensinar e transferir os seus produtos e serviços à comunidade, atuando no contexto de um mundo em transformaçáo, cujas incertezas de futuro devem preservar a essência de educar pela ciência, como missão a ser mantida no seio da academia, em acordo com Sursock e SMIDT ${ }^{6}$. Ou seja, vencer pelo conhecimento pode ser uma importante vocação universitária. Destaca ainda Mотоуама ${ }^{7}$ que, à partir do século XVII na Europa, enfatizou-se a pesquisa num clima de ensino e inovação e isso ocorreu nas universidades mais novas, que não possuíam o peso da tradição medieval.

Parece-nos ainda que o futuro está atrelado ao grau de desenvolvimento científico e tecnológico que conseguirmos estabelecer baseados no conhecimento. Foi o cumprimento desta tarefa, que transformou a Universidade em instituição produtiva, dando origem à estruturação e desenvolvimento do sistema da pósgraduação "stricto sensu". Desta maneira, entendemos que a primeira vocação e orientação da Universidade é a produção do conhecimento científico e a inovação tecnológica, entre outros importantes desafios, quando se trabalha nas fronteiras do conhecimento, em acordo com AMADIO 8 .

Alerta-nos ainda, Bento9, nesta crise social contemporânea que vivemos, sobre "o frenesim $e$ a voracidade do reformismo em curso, reveem-se em tais ambiçôes e intentam impor-se em todos os setores, incluindo a Universidade. Assim, muitos almejam minar e perverter a missão da Universidade, usurpar sua autonomia, subjugá-la para servir interesses alheios à sua matriz". E este é o maior risco que a Universidade sofre. Reconhece o Autor que há açóes que podem arruinar a sua função de mostrar as vias por onde a sociedade e a humanidade devem caminhar. Recomendaríamos importante conduta dos acadêmicos no sentido de se manterem fiéis ao compromisso histórico do desígnio da Universidade, cuja incumbência humanista, social e cultural deve ser mantida. O humanismo não foi só um método de renovar a ciência, supôs também uma mudança nos comportamentos sociais. Nesse sentido, Albert Einstein (1879-1955), observa "Não basta preparar o homem para o dominio exclusivo de uma especialidade. Passará a ser então uma espécie de máquina mas, não uma personalidade completa". Diante disso é urgente o estabelecimento da missão da Universidade, cuja atenção deve ser dada à formação e educaçáo, com efetiva repercussão para a vida social.

Portanto, destacaríamos que não basta a Universidade formar os melhores profissionais, ela tem que apresentar alto rendimento na pesquisa qualificada e de significado para a realidade social. Refere-se ainda CoHen $^{10}$ ao sistema de ciência e tecnologia como uma verdadeira alavanca para o desenvolvimento social, como uma questáo de soberania nacional na liberdade de pesquisa e na transferência de conhecimentos, entre outros importantes desafios, quando se trabalha nas fronteiras do conhecimento. Cabe, portanto, neste momento, uma reflexão sobre o papel e a ação dos principais agentes produtores e aplicadores do conhecimento.

Assim, Marques et al. ${ }^{2}$ reconhecem quais são estes agentes, entre os quais destacam universidades, governos e empresas. A Universidade tornou-se uma instituição universal, gerou uma multiplicidade de modelos, renovou sua gestão, estimulada por condições sociais emergentes, flexibilizou a formação ao lado de novas áreas de conhecimento. A pesquisa científica cresce em importância social e vemos sua credibilidade em franco e permanente progresso. 


\section{Primordios da Pós-graduação no Brasil, na USP e na EEFE-USP: características de uma liderança conquistada}

O desenvolvimento do sistema de pós-graduação no Brasil deveu-se à proliferação dos cursos superiores e da inexistência de quadros docentes habilitados para atender a demanda quantitativa e qualitativa. Restringiu-se a princípio, somente às instituições públicas de ensino superior. Em acordo com Melfi e Motoyama ${ }^{11}$, o sistema de pós-graduação foi o grande responsável pelo desenvolvimento do sistema universitário brasileiro, abrindo perspectivas relativas à formação de recursos humanos qualificados para o ensino e a pesquisa, bem como estruturou as bases para o crescimento do sistema de C\&T no país. Relatam ainda os Autores os primeiros passos para a criação da pós-graduação no Brasil, a partir da década de 1930 quando a Universidade de São Paulo e a Faculdade Nacional de Filosofia do Rio de Janeiro adotaram o modelo europeu de pós-graduação. Contudo, somente na década de 1960 a pós-graduação surgiria no Brasil como um sistema organizado nos moldes das "Graduate Schools" norte americanas.

$\mathrm{Na}$ USP foi a Portaria GR-USP 885 (25 de agosto de 1969) que criou a CCP (Coordenação Central de Pós-graduaçáo), definindo as normas de funcionamento da pós-graduação. Ela marcou a formalização nos moldes atuais e o início da pós-graduação na Universidade de São Paulo, estabelecendo critérios e designando os integrantes da CCP, promovendo assim a criação oficial dos cursos de pós-graduação no Brasil. Acrescenta ainda MотоунмA $^{7}$, que a formalização da pós-graduaçáo na USP, mesmo respondendo a uma provocação de origem federal, a partir do "Parecer Newton Sucupira", de dezembro de 1965, quando o Conselho Federal de Educação, órgão do MEC, iniciou os estudos para a regulamentação e institucionalização dos cursos de pós-graduação no Brasil e em 1969 implanta o modelo atual. Importante ainda destacar que o sistema de doutoramento instaurado na USP, desde a sua fundação em 1934 até o início da década de 1970, inspirava-se, em grau maior ou menor, especialmente nas universidades modernas alemâs e italianas e, sobretudo nas francesas.

Assim organizada, a pós-graduação brasileira constitui hoje o setor de maior êxito do sistema de ensino superior, fato que podemos interpretar também para a área da Educação Física e Esportes, cujos esforços iniciaram-se há pouco mais de 40 anos no interior de um sistema universitário marcado por muitas deficiências e dificuldades.

Com a preocupação central de estruturar o sistema da pós-graduaçáo, baseado na excelência do ensino e no alto desempenho científico-acadêmico, foi que, na gestão do Prof. Dr. MOACYR BRONDI DAIUTO como Diretor da Escola de Educação Física e Esporte da Universidade de São Paulo (EEFE-USP) gestão administrativa de 1976 a 1980, instalou-se o primeiro curso de pós-graduação "stricto sensu" da América Latina, o Mestrado em Educação Física, que iniciou suas atividades em março de 1977. Registramos ainda, a aula inaugural do referido curso proferida em 12 de abril de 1977 pelo Prof. Dr. IRANY NOVAH MORAES que desenvolveu o tema "Racionalização do trabalho intelectual do pesquisador".

Quando da criação da pós-graduação "stricto sensu", a preocupação central à época era de se buscar a melhor capacitação através da titulação universitária dos docentes participantes do sistema universitário brasileiro. Desta maneira pode-se responder as necessidades de uma Universidade cientificamente organizada e com respostas específicas, baseadas na qualidade e eficiência de seu desempenho.

Reconhecemos e destacamos a visão de futuro da EEFE-USP que, ao estruturar o início da pós-graduação "stricto sensu", o fez de maneira internacional ao apoiar-se no Programa de Cooperação e Intercâmbio Brasil \& Alemanha, quando tivemos a participaçáo e incentivo acadêmico por meio de professores, pesquisadores, especialistas e renomados cientistas alemães ministrando as primeiras disciplinas formativas para as turmas selecionadas de mestrandos, no período de 1976 a 1980. Desta maneira valorizouse e deu-se a devida importância para a capacitação acadêmica com base internacional, relaçóes estas intencionalmente praticadas e planejadas há 40 anos atrás, cuja herança permanece até os dias atuais como um verdadeiro centro de referência internacional para a produção do conhecimento científico-acadêmico em Educação Física e Esporte, reconhecimento este consolidado pela nota 7 (sete) de avaliação da Coordenação de Aperfeiçoamento de Pessoal de Nível Superior do Ministério da Educação (CAPES$\mathrm{MEC})$, que atribuiu portanto, nota de excelência ao programa para o triênio 2010 a 2012, apoiado entre outros fatores pelo grau de internacionalizaçâo 
alcançado na EEFE-USP. Dessa maneira, nasceu o Curso de Mestrado em Educação Física na EEFEUSP ainda em 1977.

Através de comitês especializados por área de conhecimento a CAPES-MEC procede a avaliaçáo dos programas, referência esta nacional e internacional para a conceituação dos programas de pós-graduação. Assim, o programa da EEFE-USP recebeu distinção e reconhecimento de excelência desde 2010, demonstrando ser hoje um programa consolidado e estar desempenhando importante papel dentro do sistema de pós-graduação na Universidade de São Paulo e no País.

A importância, o papel multiplicador e a positiva influência deste programa de pós-graduação para a concretização da Educação Física e do Esporte como ciência, são aspectos indiscutíveis e realmente necessários, pois observamos que, após 40 anos de Mestrado (1977 a 2017), o programa atingiu seus objetivos de preparação competente de recursos humanos em nível de pós-graduação, preparação esta que suportará as novas orientações paradigmáticas oriundas da sociedade que deverá retroalimentar o sistema com demandas próprias do meio a que serve.

Desde a sua criação a pós-graduação da EEFEUSP desempenha um importante papel dentro do sistema da pós-graduação brasileira, primeiro pela qualidade do pessoal titulado que vem atuando de maneira a intervir significativa e positivamente no domínio de conhecimento da área e em segundo lugar por capacitar mestres e doutores com sólida formação e bem preparados, para o mercado de trabalho através de seus cursos bem avaliados pelo sistema nacional de pós-graduação. Esta evidência demonstra de forma efetiva a excelência de formação dos recursos humanos altamente qualificados e com visão de inclusão internacional desde a sua criação, em acordo com AMADIO ${ }^{12}$. É assim que a EEFE-USP está proporcionando para o sistema universitário brasileiro sua positiva contribuição dentro da área do conhecimento.

Relacionamos a seguir, nominalmente os docentes e discentes que participaram da comissão de pósgraduação no ano da instalação do curso Mestrado em Educação Física. O Reitor da Universidade de São Paulo era o Prof. Dr. ORLANDO MARQUES DE PAIVA (1973 a 1977), o Presidente da Coordenação Central de Pós-Graduação, depois Câmara da PósGraduação do Conselho de Ensino, Pesquisa e Extensão da Universidade de São Paulo era o Prof. Dr. PASCHOAL ERNESTO AMÉRICO SENISE
(1969 a 1987) e o Presidente da CAPES-MEC era o Prof. Dr. DARCY CLOSS (1974 a 1979). Ressalte-se que a referida composição estava em conformidade com a estrutura estatutária e regimental vigente para o sistema acadêmico na Universidade de São Paulo, assim como regimento e normas da comissão de pós-graduação da EEFE-USP. Em 6 de maio de 1976, por intermédio da portaria n. 74/76 do Diretor da EEFE-USP, designou-se a Comissão de Pós-graduação da EEFE-USP para elaboração do respectivo Regimento Interno. Essa comissão ficou assim constituída, Mario Nunes de Sousa (Presidente), Jarbas Gonçalves e Maria Augusta Peduti Dal'Molin Kiss (Membros) e a Senhora Thereza Zélia Pavan como Secretária. Reuniu-se a referida comissáo no período de 11 de maio de 1976 a 29 de março de 1977, por 27 sessóes até a estruturação final do curso de pós-graduação "stricto sensu", Mestrado em Educação Física, junto aos órgãos colegiados da EEFE-USP e órgãos centrais da Reitoria da USP bem como, CAPES-MEC.

Após a estruturação inicial de seu regimento interno, organização da grade curricular do regime didático do curso e credenciamento do quadro de orientadores, a referida comissão procedeu a seleção da primeira turma de ingressantes, conforme edital, portanto dos mestrandos em Educação Física da EEFE-USP. Inscreveram-se ao primeiro processo seletivo 159 candidatos, entre docentes do ensino superior, técnicos esportivos e líderes de organizaçóes publicas e privadas brasileiras e estrangeiras. Após a finalização das etapas do referido processo, foram selecionados 30 alunos que constituíram a primeira turma de mestrandos da EEFE-USP, são eles: Ana Maria Pellegrini, Carlos Catalano Calleja, Celso Carvalho Bandiera, Clodoaldo Paulo de Mesquita, Fabio de Barros Gomes, Fernando Bocolini, Horácio Accioly Junior, João Luongo, José Alberto Aguilar Cortez, José de Souza Teixeira, José Medalha, Kenji Kido, Koiti Anzai, Laercio Elias Pereira, Lourinaldo Rodrigues do Espirito Santo, Luiz Alberto Lorenzetto, Luiz Roberto Zuliani, Maria Alice Magalhaes Navarro, Maria Beatriz Rocha Ferreira, Mauro Antonio Guiselini, Mauro Gomes de Mattos, Nestor Soares Públio, Nuno Cobra Ribeiro, Paulo Murilo Alves Iracema, Paulo Roberto Gomes de Lima, Paulo Roberto de Oliveira, Renata Elza Stark, Rubens Lombardi Rodrigues, Valdir José Barbanti, e Valdir Pagan Peres.

Assim em março de 1977, após o ingresso da primeira turma do curso de pós-graduação "stricto sensu” Mestrado em Educação Física, a referida 
comissão de pós-graduação da EEFE-USP é reestruturada e passa a ter a seguinte composição: Mario Nunes de Sousa (Presidente), Jarbas Gonçalves e Maria Augusta Peduti Dal'Molin Kiss (Membros), Aluízio de Queiroz Telles e José Geraldo Massucato (Suplentes), Lourinaldo Rodrigues do Espirito Santo e Laercio Elias Pereira (Representantes Discentes) e a Senhora Thereza Zélia Pavan como Secretária.

A partir dessa resumida síntese e ainda preocupados com o futuro da Educação Física e Esporte como ciência e seus rumos dentro da própria universidade, foi que após 12 anos do curso de Mestrado em Educação Física na EEFE-USP, em 1988 estruturou-se o curso de pós-graduação "stricto sensu" Doutorado em Educação Física, que iniciou suas atividades em agosto de 1989 e tendo como área de concentração "Biodinâmica do Movimento Humano". Registre-se ainda que nessa altura já estava instalada a Pró-Reitoria de Pós-graduação da USP, tendo como Pró-Reitor o Prof. Dr. OSWALDO UBRÍACO LOPES (1987 a 1992), na gestão reitoral do Prof. Dr. JOSÉ GOLDEMBERG (1986 a 1990) e era Diretor da EEFE-USP o Prof. Dr. ERASMO MAGALHÁES CASTRO DE TOLOSA (1988 a 1991). Integravam a comissão de pós-graduação da EEFE-USP, por ocasião da formulação da proposta e instalação do curso de pós-graduação "stricto sensu" Doutorado em Educação Física: Alberto Carlos Amadio (Presidente), Rubens Lombardi Rodrigues, Maria Alice Magalhães Navarro e Carlos Eduardo Negrão (membros), Marize Cisneiros Costa e Jocimar Daólio (representantes Discentes), e Celia Yamaoka e Maria de Lourdes da Silva (Secretárias).

A principal característica da nova proposta e desafio acadêmico estava na dimensão interdisciplinar do conhecimento cientifico, que o projeto abordava, fundamentando suas bases para a interpretação do movimento humano. Para tanto, estruturou-se base de cooperação interunidades dentro da Universidade de São Paulo. Assim, além da Escola de Educação Física e Esporte, instituição proponente e futura sede do novo curso, participaram a Faculdade de Medicina (FM-USP) e Escola Politécnica (EPUSP). Definiu-se deste modo, as necessárias bases estruturais para o desenvolvimento do curso, a saber: oferta de disciplinas e créditos formativos, atenção às atividades científicas em conformidade com projetos de pesquisa e apoio dos laboratórios, atuação de orientadores com produção temática no contexto da área de concentração para a capacitação em alto nível de Doutores em Educação Física. Reconhecia-se a importância, o papel multiplicador e a positiva influência do curso de doutorado para a consolidação da Educação Física como ciência, após 12 anos do curso de mestrado e a inexistência de qualquer outro curso de doutorado relacionado com a área no País e na América Latina, pois o mestrado vinha se transformando num fim em si mesmo, comprometendo a formação e o crescimento do docente e do pesquisador.

Portanto, através da presente descrição destacamos o intrínsico pioneirismo em ambos os cursos, ou seja, pós-graduação "stricto sensu” Mestrado e Doutorado em Educação Física no Brasil e na América Latina. Registramos também os melhores agradecimentos e apresentamos nossos sinceros reconhecimentos a cada um destes ilustres professores e/ou alunos, à época, pela efetiva contribuição e serviços prestados nesta caminhada de 40 anos superando desafios e galgando importantes avanços para a consolidação da pós-graduação "stricto sensu" em Educação Física e Esporte na EEFE-USP.

\section{Um programa criado com inspiracão e vocação na internacionalização do ensino e da pesquisa}

A internacionalização da educação superior tem sido um importante desafio que as universidades brasileiras, em geral, vêm enfrentando nas últimas décadas. A formalização da pós-graduação na USP, em acordo com MoтоунмA ${ }^{7}$, abre-se para uma perspectiva internacional de produção científica identificada por LE GoFF ${ }^{13}$, já nas instituiçôes medievais. Na USP, ficou caracterizada pela expressão geopolítica do século XX, quando o conhecimento foi identificado ao poder, tanto na sua natureza politica como econômica.

Na EEFE-USP, em particular, esta temática tem merecido atenção especial da comunidade acadêmica. Muitas foram as iniciativas de incremento à internacionalização ao longo destes 40 anos passados. Assim, programas específicos 
incentivaram o intercâmbio, a participação de docentes e estudantes em congressos, seminários, estágios, feiras e/ou fóruns no exterior, através do desenvolvimento de relaçôes com agências e instituiçôes com programas especiais e projetos de apoio e fomento à vinda de docentes e pesquisadores do exterior, por meio do programa de professores visitantes, entre outros.

Em especial, destacamos decisiva ação estruturada e desenvolvida no período 1976 a 1980. Refirome ao "Programa de Cooperaçáo e Intercâmbio para o desenvolvimento do Esporte no Brasil" (SPORTFÖRDERUNG IN BRASILIEN, 1963 a 1982), em acordo com Diem ${ }^{14}$, programa de cooperação e intercâmbio entre entidades e agências governamentais representativas do Brasil e da Alemanha no período de 1963 a 1982. Portanto o programa era de abrangência nacional, considerando ações intergovernamentais, representados por órgão federais que preocuparam-se com o apoio para atendimento de infra estrutura de pessoal e material, à partir de diagnósticos e perspectivas regionais e locais, selecionadas e voltadas à formação, pesquisa e desenvolvimento.

Sinteticamente, para a Universidade de Sáo Paulo, junto à Escola de Educaçáo Física e Esporte (EEFE-USP) o Programa centralizou suas açóes em três grandes projetos, a saber: 1) criação da Pós-graduação em Educação Física; 2) criação da Academia de Treinadores Esportivos; e 3) criação do Instituto de Biomecânica.
De acordo com Riehle ${ }^{15}$, o PNED (Plano Nacional de Educação Física e Desporto), do MEC-DED empenhava-se em elevar o nível de preparação do professor de Educaçáo Física. Esse aperfeiçoamento planejou-se nas Universidades, no quadro dos cursos de pós-graduaçáo, a FIGURA 1 mostra a natureza escolar e a respectiva estrutura dos cursos de pós-graduação. Estruturou-se dessa maneira um Plano Nacional de pós-graduaçáo em Educação Física e formação de Treinadores esportivos, apoiados e aplicados, inicialmente, às seguintes universidades brasileiras: Universidade de São Paulo, Universidade Federal de Santa Maria, Universidade Federal de Pernambuco e Universidade Federal de Minas Gerais. Dessa maneira teve início no ano de 1976, concomitantemente nessas quatro instituições, um curso de especialização em Biomecânica do Esporte (pós-graduação "lato sensu"), como curso de preparação para o inicio da pós-graduação "stricto sensu" (mestrado em Educaçáo Física) e assim teve inicio o referido Plano Nacional de Pós-graduação e formação de Treinadores esportivos, como ilustrado na FIGURA 1. Observa-se intrínsica dependência entre a formação de pós-graduados pelas Universidades e a capacitaçáo de Treinadores com carreira, planos e níveis específicos de atuaçáo profissional junto a clubes esportivos e/ou seleçóes esportivas, estas controladas e administradas, à época, pelos órgãos da área federal Ministério de Educação e Cultura, Departamento de Educação Física e Desportos, Conselho Nacional de Desportos (MEC-DED/CND). 


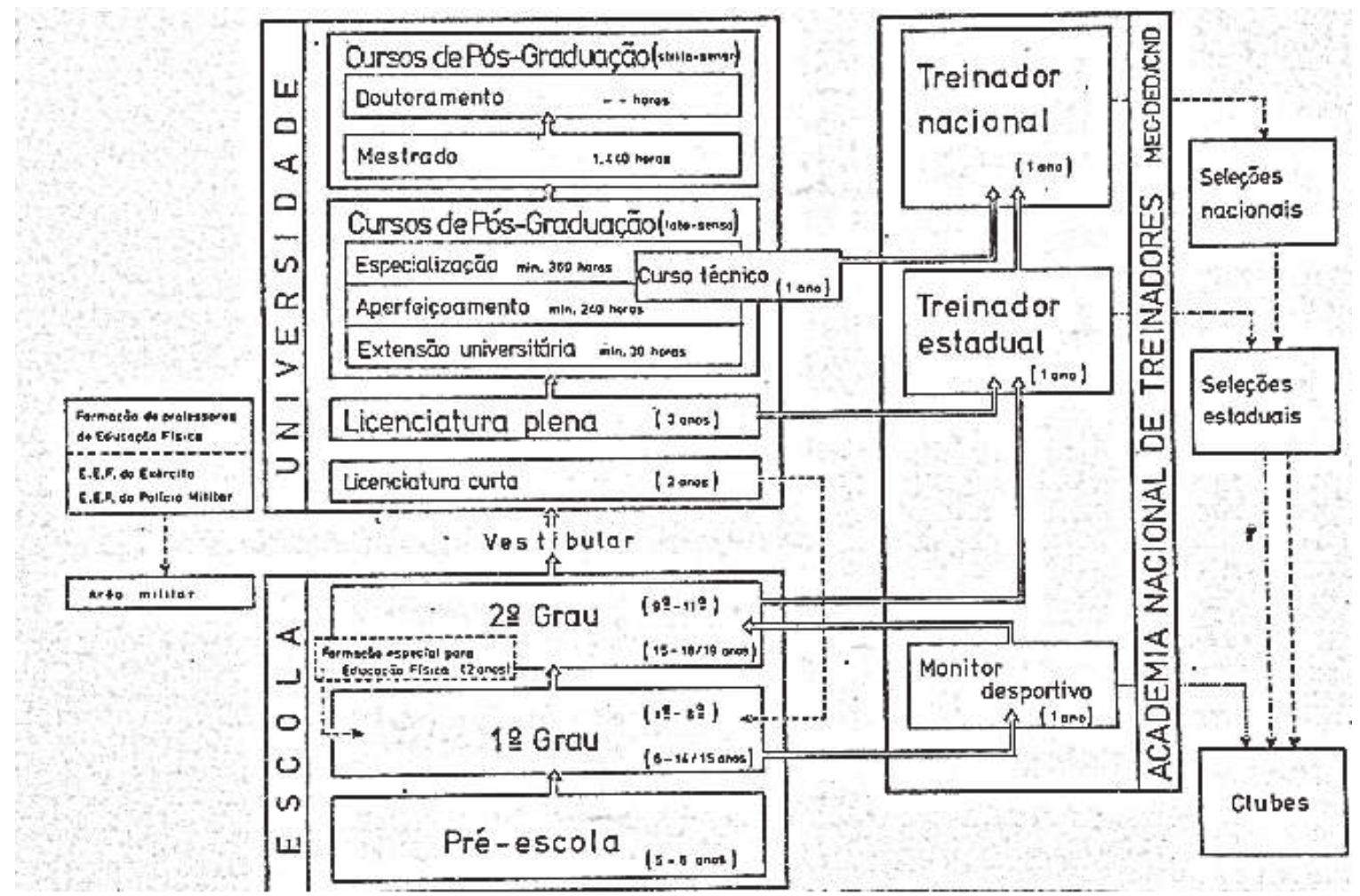

FIGURA 1 - Plano Nacional de Pós-graduação em Educação Física e formação de treinadores esportivos, segundo proposta esquemática estrutural: Escola, Universidade e Academia de Treinadores, no contexto do "Programa de Cooperação e Intercâmbio para o desenvolvimento do Esporte no Brasil" (SPORTFÖRDERUNG IN BRASILIEN, 1963 a 1982), DIEM ${ }^{14}$.

O primeiro curso de pós-graduação "stricto sensu" em nível de mestrado, na área da Educação Física no Brasil e na América Latina iniciou-se portanto, em 12 de abril de 1977 na Escola de Educação Física e Esporte da USP. Na FIGURA 2 apresentamos, em acordo com RIEHLE ${ }^{15}$, quais os Estados brasileiros estão presentes nessa proposta de curso, sendo que, os cursos de pósgraduação em nível de mestrado nas Universidades Federais de Minas Gerais (Belo Horizonte) e Rio Grande do Sul (Santa Maria), ainda estavam em planejamento. 


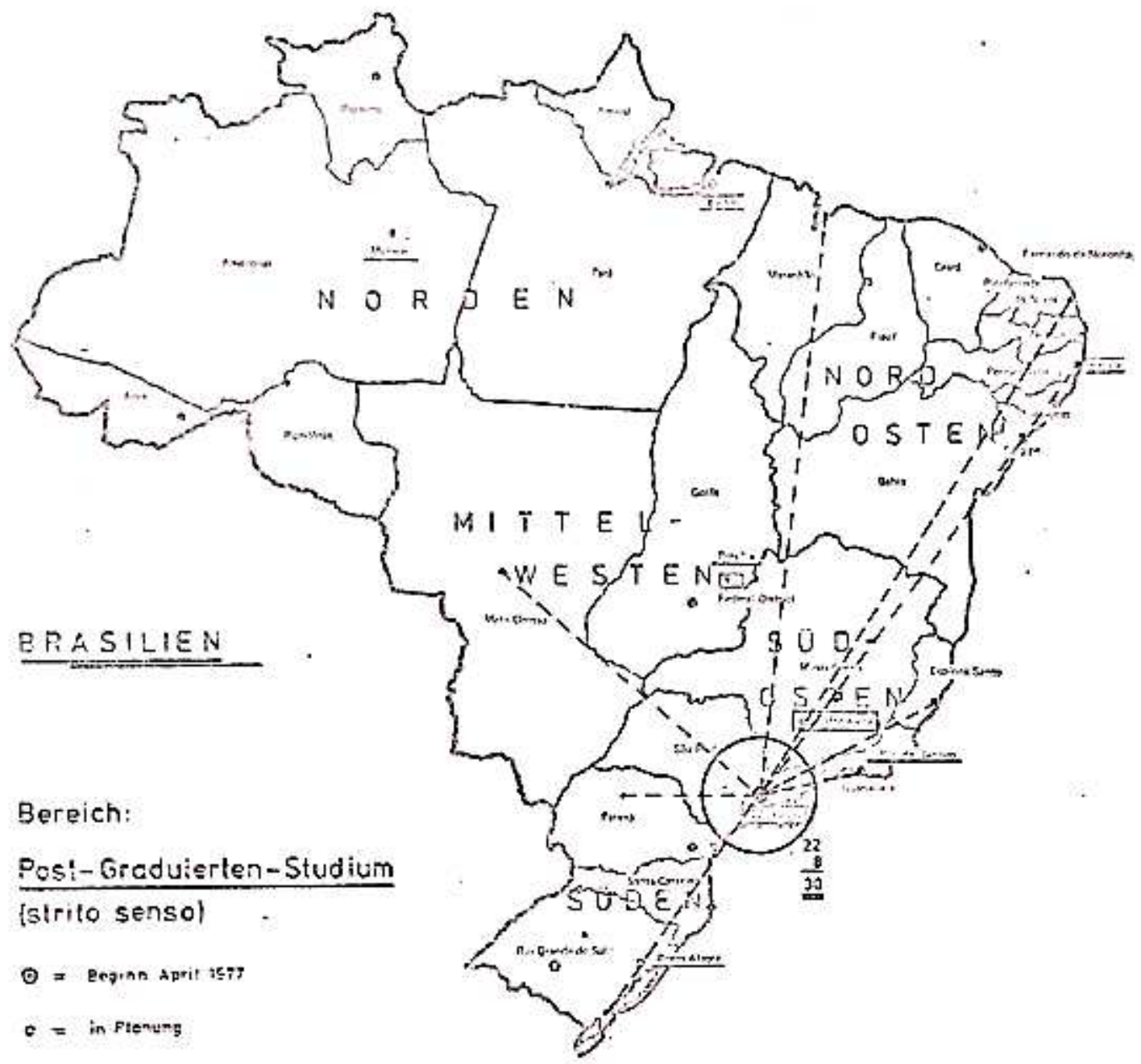

FIGURA 2 - Desenvolvimento Regional da Pós-graduação “stricto sensu” Mestrado em Educação Física no Brasil, cursos de mestrado planejados à partir do Curso de São Paulo iniciado em abril de 1977, segundo proposta do "Programa de Cooperação e Intercâmbio para o desenvolvimento do Esporte no Brasil" (SPORTFÖRDERUNG IN BRASILIEN, 1963 a 1982), DIEM ${ }^{14}$.

Outra importante atividade, ainda no contexto do referido Programa de Cooperação e Intercâmbio para o desenvolvimento do Esporte no Brasil, entre os Projetos propostos para a Universidade de São Paulo, em acordo com Diem ${ }^{14}$, foi a estruturaçáo do Projeto Internacional n. 75.9026.8/4111, em acordo com RieHLE ${ }^{15}$, que propunha a criação do Instituto de Biomecânica da EEFE-USP (Autores do projeto: Prof. Dr. WOLFGANG BAUMANN - IfB/DSHS, Prof. Dr. HARTMUT RIEHLE GTZ/DSHS e Prof. Dr. HARTMUT HEINRICH GRABERT- EEFE-USP). O projeto seguiu orientações técnicas, planos e plantas que foram desenvolvidas pelo FUNDUSP que também foi o órgão responsável pela edificação e construção da obra de $120 \mathrm{~m}^{2}$, projeto concluído em agosto de 1979 e que abrigou o que mais tarde denominouse Laboratório de Biomecânica da EEFE-USP, tendo iniciado suas atividades de ensino, pesquisa e extensão em 18 de Outubro de 1988.

Foram as seguintes entidades governamentais do BRASIL e da ALEMANHA, apoiadoras e financiadoras do Projeto n. 75.9026.8/4111, a saber: República Federativa do Brasil: USP/ EEFE (Universidade de São Paulo, Escola de Educação Física e Esporte), FUNDUSP (Fundo de Construçôes da Universidade de São Paulo), e MEC/DED (Ministério de Educação e Cultura, Departamento de Educação Física e Desportos). Bundesrepublik Deutschland: BMI/GTZ/BISP 
(Bundesministerium des Innern, Gesellschaft für Technische Zusammenarbeit, Bundesinstitut für Sportwissenschaft), DSHS (Deutsche Sporthochschule Köln), e IfB/DSHS (Institut für Biomechanik, Deutsche Sporthochschule Köln).

Foi decisivo todo o empenho e esforço empreendido para a inserção da EEFE-USP no referido projeto internacional e oportuna a participação de professores alemães no recém criado curso de pós-graduação - Mestrado em Educação Física. Estamos seguros em afirmar que o Programa de Cooperação BRASIL \& ALEMANHA em muito contribuiu para a criação do referido curso de Mestrado. Grande parte da carga didática inicial, bem como a estruturação da pesquisa científica do curso de mestrado, desenvolveu-se com o apoio do referido Programa de Cooperação.
Foi ainda necessário estruturar-se organicamente a administração acadêmica da EEFE-USP para que pudesse abrigar no seu contexto as atividades inerentes ao ensino e à pesquisa em apoio à pósgraduação, que estava em processo de instalação. Desse modo apresentamos o registro das adequaçóes funcionais e de pessoal na composição do organograma institucional da EEFE-USP, ajustado com regimento e estatuto da universidade. A FIGURA 3, ilustra as adequaçóes de estrutura administrativa e acadêmica, da EEFE-USP em 1971, vistas à implantação da Pós-graduação "stricto sensu" em Educação Física, seus colegiados hierárquicos e órgãos administrativos, com especial atenção à Coordenadoria de Pesquisas, colegiado estruturado para atender à principal demanda no novo curso visando a formaçáo do pesquisador em áreas selecionadas e de interesse científico.
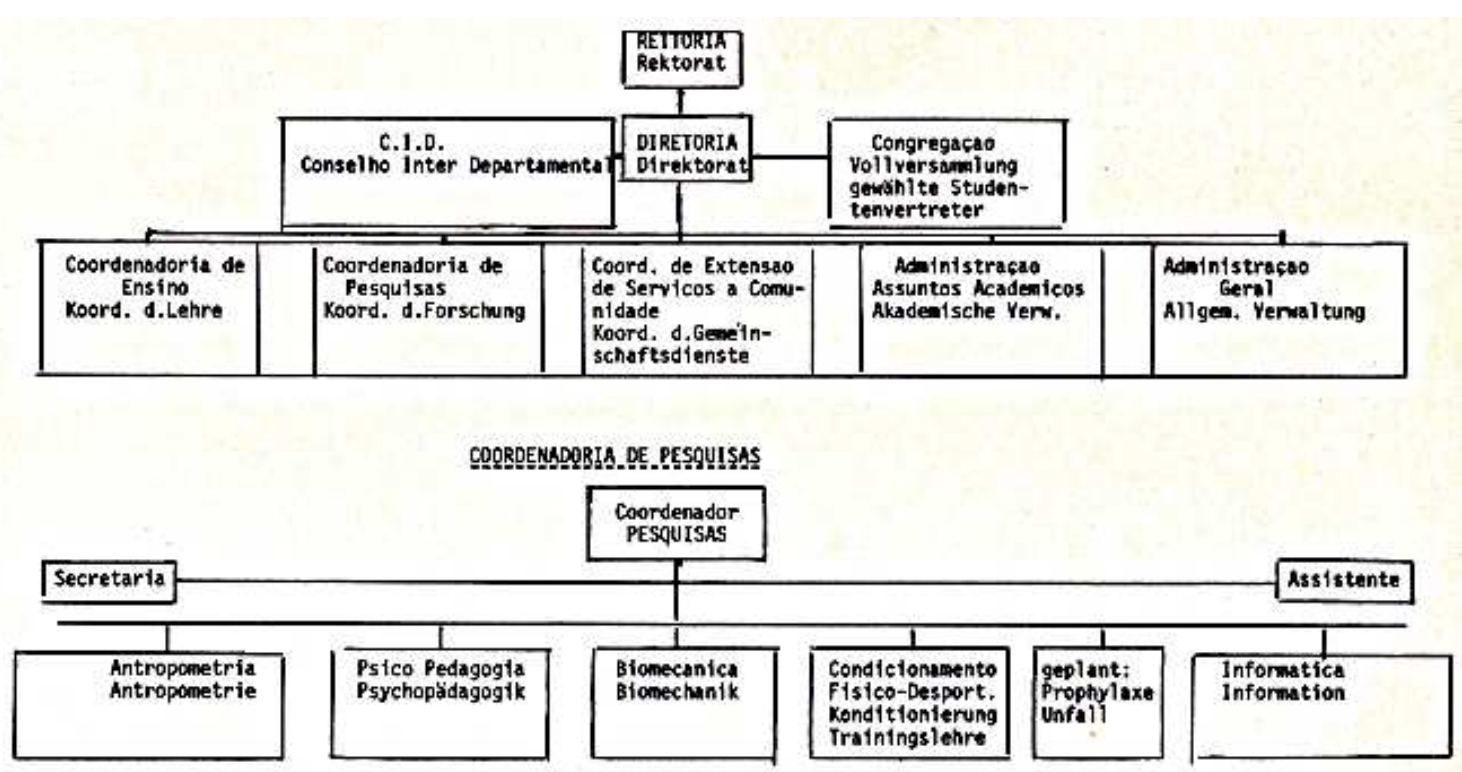

FIGURA 3 - Organograma funcional da EEFE-USP em 1971, reformulado para atender às demandas do novo Curso de Pós-graduação "stricto-sensu”, Mestrado em Educação Física, segundo proposta do "Programa de Cooperação e Intercâmbio para o desenvolvimento do Esporte no Brasil" (SPORTFÖRDERUNG IN BRASILIEN, 1963 a 1982), DIEM ${ }^{14}$.

Para o referido período, 1976 a 1980, portanto, no contexto do Programa de Cooperação e Intercâmbio para o desenvolvimento do Esporte no Brasil, em acordo com Diem ${ }^{14}$, contamos com os seguintes professores visitantes, especialistas selecionados segundo áreas de interesse e oriundos de distintas Universidades e Institutos de Pesquisa da Alemanha, que atuaram na preparação científica acadêmica, no inicio da pós-graduação "stricto sensu", Mestrado em Educação Física da EEFE-USP, a saber:

\section{6}

1. Prof. Dr. Hermann RIEDER e Prof. Dr. Klaus BÖS, Universität Heidelberg (Setembro e Outubro): Curso de especializaçáo em Psicomotricidade. Curso preparatório para o exame de seleção da primeira turma de Mestrado que iniciou o curso em 1977.

2. Prof. Dr. Eduard AMTMANN, Medizinische Hochschule Hannover e Prof. Dr. Hartmut 
RIEHLE, Deutsche Sporthochschule Köln (Setembro e Outubro): Curso de especializaçáo em Biomecânica do Esporte. Curso preparatório para o exame de seleção da primeira turma de Mestrado que iniciou o curso em 1977.

\section{7}

1. Prof. Dr. Burghard BESSAI e Prof. Dr. Siegfried HUMMEL, Universität Osnabrück (Setembro e Outrubro): Disciplina para o mestrado em Educação Física - Administraçáo, Organizaçáo e Direito Esportivo.

2. Prof. Dr. Jürgen STEGEMANN e Prof. Dr. Ulrich TIBES, Deutsche Sporthochschule Köln (Setembro e Outubro): Disciplina para o mestrado em Educação Física - Fisiologia do Esforço.

\section{8}

1. Prof. Dr. Renate SCHOLTZMETHNER e Prof. Dr. Sigrid DORDEL, Deutsche Sporthochschule Köln (Setembro e Outubro): Disciplina para o mestrado em Educação Física Ginástica Escolar Especial e Reabilitaçáo.

2. Prof. Dr. Frieder ROSKAM, Prof. Dr. Hanskarl SCHÖNFELD e Prof. Dr. Wolfgang THIES, Bundesinstitut für Sportwissenschaft (Outubro e Novembro): Disciplina para o mestrado em Educação Física - Arquitetura Esportiva.

\section{9}

1. Prof. Dr. Hans LENK, Universität Karlsruhe (Março): Disciplina para o mestrado em Educação Física - Filosofia e Sociologia do Esporte.
2. Prof. Dr. Wolfgang BAUMANN, Deutsche Sporthochschule Köln (Março e Abril): Disciplina para o mestrado em Educação Física - Biomecânica do Esporte.

\section{0}

1. Prof. Dr. Burgahrd BESSAI e Prof. Dr. Siegfried HUMMEL, Universität Osnabrück (Setembro e Outubro): Disciplina para o mestrado em Educação Física - Administraçáo, Organizaçáo e Direito Esportivo.

2. Prof. Dr. Gerhard HECKER e Prof. Dr. Ralf ERDMANN, Deutsche Sporthochschule Köln (Outubro e Novembro): Disciplina para o mestrado em Educação Física - Pedagogia e Didática do Esporte.

Tendo como pressuposto, a ideia de que na universidade contemporânea o conhecimento, as parcerias, os intercâmbios devem ser cada vez mais permeáveis às ideias de colaboração, interdisciplinaridade e internacionalização, foi que se estruturou, 40 anos atrás, na pós-graduação da EEFE-USP, o referido curso de Mestrado em Educação Física, firmando o conceito de intercâmbio internacional acadêmico, de referências e consequências positivas para uma sólida base e concepção da pós-graduação do futuro. Essas repercussôes muito nos orgulha e nos ensina como foi que a pós-graduação da EEFE-USP nasceu com vocação internacional e portanto, visionária desde o seu princípio, ocupando-se de inter-relaçóes e cooperaçóes com parceiros do exterior, como apontada por Le $\operatorname{GoFF}^{13}$ sendo a base fundamental de sustentabilidade internacional científico-acadêmica.

\section{Considerações finais: perspectivas para o futuro}

\begin{abstract}
Vivemos integrados numa sociedade em permanente evolução, com transformações científicas e tecnológicas frequentes e que tem por objetivo ser democrática, cientificamente orientada e que deva ser capaz de interagir com o desenvolvimento sócio-econômico dos seus segmentos. É cada vez mais importante a participação do sistema de pós-graduação neste contexto, não apenas caracterizada pela capacitação de recursos humanos em alto nível de qualificaçáo, como, principalmente, pela capacidade de produção técnico-científica,
\end{abstract}

considerando-se o importante valor agregado do conhecimento para o desenvolvimento humano.

A pós-graduação caracteriza-se atualmente, na universidade moderna, como uma cúpula de estudos, sistema especial exigido pelas condiçóes da pesquisa cientifica e pelas necessidades de treinamento avançado. Ou seja, estamos preocupados, em vislumbrar o futuro, traçando perspectivas e as necessárias adequaçōes dos cursos de pós-graduação para atender expectativas da realidade social do amanhã, novas demandas, novo perfil de seus 
agentes, novos desafios científicos e tecnológicos, enfim, em como a universidade se comportará no próximos anos e em especial quais serão os desafios da pós-graduação produtiva e importante para o sistema social no qual se insere.

Assim, o entendimento da contribuição deste sistema de pós-graduação é fundamental para que continuemos a investir esforços que se traduzam na mais profícua concretizaçáo dos objetivos delineados para a contínua e crescente evolução da pós-graduação "stricto sensu" no Brasil. Conclui-se sobre as positivas expectativas quanto a formação de pesquisadores e qualificação de professores, mantendo-se os esforços centrados no sistema de pós-graduação que também responde pela capacidade de pesquisa e inovação científica e tecnológica hoje instalada no País.

Reiteramos a importância e a positiva expectativa na evolução do sistema pois consideramos tratar-se a pós-graduação de uma das faces mais bem sucedidas da politica do ensino superior brasileiro e ainda para a consolidaçáo da ciência e da tecnologia em pról do desenvolvimento humano. $\mathrm{O}$ investimento na pesquisa científica e tecnológica não é apenas uma coadjuvante passiva nessa projeção para o futuro, mas conquistas que tanto beneficiam a sociedade, e que precisam ser protegidas de outras politicas que, eventualmente, coloquem em risco sua estrutura, importância e o papel que hoje ela cumpre com eficiência.

O ensino superior, portanto, é preocupação permanente, ainda que tenhamos muitos outros desafios a enfrentar. Schwartzmann ${ }^{16}$, destaca o importante papel das universidades de classe internacional, sendo estas referência para se lidar com a globalização crescente do ensino superior, pois as universidades de classe internacional desenvolvem, além da ciência e tecnologia, também a cultura, formação geral, conhecimento e capacidade de entender o País e o mundo. Pontua ainda VIlela ${ }^{17}$ que, fazer parte do mundo globalizado é papel dessas universidades, permitido conviver com os desafios e enfrentá-los sem perder de vista a excelência e a qualidade.

Cabe-nos ainda salientar o relevante papel do Prof. MOACYR BRONDI DAIUTO, Diretor da EEFE-USP (1976 a 1980), com a criação da pósgraduação "stricto sensu", Mestrado em Educaçáo Física em março de 1977. Como apresentado, foi também com a liderança do referido professor que a EEFE-USP participou ativamente do Programa de Cooperação e Intercâmbio para o desenvolvimento do Esporte no Brasil ${ }^{14}$, inserindo a pós-graduação pioneira no Brasil e na América Latina, no contexto internacional.

A importância da criação do curso de pósgraduação "stricto sensu" Mestrado em Educação Física na EEFE-USP, pelas oportunidades pessoais e institucionais geradas ao longo desses produtivos 40 anos passados, foi fruto de ação e visão de futuro institucional com vocação acadêmica e orientado à internacionalizaçáo do ensino e da pesquisa. Desta forma, pode-se praticar, desde o princípio, intercâmbio científico e cultural, valorizar a diversidade na formação acadêmica do pós-graduando, procurando superar as fronteiras do conhecimento. O sucesso do sistema de pósgraduação deveu-se sobretudo por tratar-se de um sistema harmônico, homogêneo e balizado por legislação clara e única. Essas são razóes e motivos que certamente representarão a garantia de sucesso e desempenho futuro, suprindo com eficiência a demanda de formaçáo de mestres e doutores em Educação Física para o País.

Com esse registro histórico, prestamos nossa justa e sincera homenagem, à EEFE-USP, reconhecendo ter sido esse Curso de Pós-graduação "stricto sensu" Mestrado em Educação Física, importante baluarte inspirador, de memória e referência permanente, um verdadeiro divisor de águas que deixou indelével marca na história do ensino superior brasileiro e no desenvolvimento da Educação Física e do Esporte como ciência na EEFE-USP, bem como no Brasil. Ressaltamos finalmente, o esforço para se alcançar cada vez maior visibilidade internacional. Esforço esse decisivo e que deve ser contínuo, integrando ensino, pesquisa e inovação científica e tecnológica aplicada, apoiado fundamentalmente no importante ról de convênios e intercâmbios de cooperação institucionais nacionais e/ou internacionais em vigência e de prática regular na EEFE-USP com todos os seus grupos de pesquisa ativos, prática essa iniciada com sucesso, há 40 anos atrás.

Registramos importantes avanços com a internacionalização da Pós-graduação quer na qualidade de formação dos docentes e pesquisadores, como principalmente no produto final das investigações para a qualidade de vida e bem estar do cidadão. Finalmente, nossas expectativas para que no futuro, tenhamos a evolução de um enquadramento legal, jurídico e normativo dos programas de pós-graduação de maneira a atender os avanços do conhecimento científico para sua internacionalização sem constrangimentos. Estamos seguros que o capital cultural evolui 
permanentemente trazendo cada vez mais novas sinergias, novas atitudes, desafiadoras e inovadoras expectativas para o docente e o pesquisador na Pósgraduação "stricto sensu".

\section{Referências}

1. Schenberg M. Formação da mentalidade científica. Cad Estudos Avançados. 1991;12:123-51.

2. Marques AT, Amadio AC, Gaya A. Pesquisas moçambicanas em ciências do desporto: avaliação do seu impacto: análise das publicaçóes na área da actividade física e saúde em Moçambique nos últimos 25 anos. Rev. Cient. UEM. 2016;1:100-15.

3. Chaparro C. A ciência no mundo antigo e sua transmissão ao ocidente. In: Tejerina F, editor. A universidade uma história ilustrada. Madrid: Banco Santander/Turner; 2010. p.3-37.

4. Peset M. A europa e as universidades. Tejerina F, editor. A universidade uma história ilustrada. Madrid: Banco Santander/ Turner; 2010. p.41-69.

5. Giorgetti de Brito LR. A universidade do futuro. In: Vilela S, Lajolo FM. USP 2034: planejando o futuro. São Paulo: Editora da Universidade de São Paulo; 2009. p.187-211.

6. Sursock A, Smidt H. Trends 2010: a decade of change in European Higher Education. Brussels: European University Association; 2010.

7. Motoyama S, organizador. Construindo o futuro: 35 anos de pós-graduação da USP. São Paulo: Editora Parma; 2004.

8. Amadio AC. Trajetória da pós-graduação stricto sensu na Escola de Educação Física e Esporte da Universidade de São Paulo após 25 anos de produção acadêmica. Rev Bras Ciênc Esporte. 2003;24:27-47.

9. Bento JO. Por uma Univercidade anticonformista. Belo Horizonte: Instituto Casa da Educação Física/UNICAMP; 2014. (Fórum Pensamento Estratégico - PENSES, 2).

10. Cohen J. Science in Latin America: publication trends uneven growth. Science. 1995;267:808.

11. Melfi AJ, Motoyama S. O ensino superior brasileiro. In: Tejerina F, editor. A universidade uma história ilustrada. Banco Santander, Turner, pp. 403-429, 2010.

12. Amadio AC. Consolidação da pós-graduação stricto sensu da Escola de Educação Física e Esporte da Universidade de São Paulo: trajetória acadêmica após 30 anos de produção. Rev Bras Educ Fís Esporte. 2007;21:N esp:25-36.

13. Le Goff J. Os intelectuais na Idade Media. Rio de Janeiro: José Olympio; 2003.

14. Diem L. Sportförderung in Brasilien: Bericht über die Förderung des Sports in der Föderativen Republik Brasilien durch die Bundesrepublik Deutschland 1963 bis 1982. Sankt Augustin: Verlag Hans Richarz; 1984.

15. Riehle H. Relatório: promoção esportiva no Brasil. [Local desconhecido]: [Editora desconhecida]; 1977. Projeto n. 75.9026.8/411.

16. Schwartzmann SA. Universidade de São Paulo e a questão universitária no Brasil. Seminário sobre o Ensino Superior no Brasil; 9 de novembro de 2004, São Paulo, SP, Brasil. São Paulo: Instituto de Estudos Avançados/Universidade de São Paulo; 2004.

17. Vilela S. USP: uma universidade de classe mundial. In: Vilela S, Lajolo FM. USP 2034: planejando o futuro. São Paulo: Editora da Universidade de São Paulo; 2009. p.13-43.

$$
\begin{array}{r}
\text { ENDEREÇO } \\
\text { Alberto Carlos Amadio } \\
\text { Escola de Educação Física e Esporte - USP } \\
\text { Av. Prof. Mello Moraes, } 65 \\
\text { 05508-030 - São Paulo - SP - BRASIL } \\
\text { e-mail: acamadio@usp.br }
\end{array}
$$

18 • Rev Bras Educ Fís Esporte, (São Paulo). 2017 Ago; 31(N esp):7-18. 